\title{
Duas fontes documentais para o estudo dos preços dos escravos no Vale do Paraíba paulista
}

Renato Leite Marcondes ${ }^{1}$

Universidade de São Paulo

José Flávio Motta ${ }^{2}$

Universidade de São Paulo

\section{RESUMO}

Estudam-se os preços dos escravos em quatro localidades do Vale do Paraíba paulista com base na comparação de duas distintas fontes documentais no período 1872-1874. Para Cruzeiro e Lorena, utilizou-se a Lista de Classificação para Emancipação. Para Guaratinguetá e Silveiras lançou-se mão das escrituras de compra e venda de cativos. As semelhanças e diferenças observadas refletem as características de cada uma das fontes aludidas. As escrituras de compra e venda fornecem os preços dos escravos de forma mais próxima dos valores de mercado, todavia abrangendo parcela não tão representativa da população cativa vis-à-vis a Lista de Classificação. Esta última, por sua vez, ao passo que caracterizada pela maior abrangência, encerra maiores imprecisões quando se trata das avaliações individuais dos escravos arrolados.

Palavras-chave: preços dos escravos; escravidão; economia cafeeira,

\section{ABSTRACT}

We study slave prices in four localities of the Vale do Paraíba (São Paulo) based on a comparison of two distinct primary sources in the period 1872-1874. For Cruzeiro and Lorena, we used the Lista de Classificação para Emancipação. For Guaratinguetá and Silveiras, we used the escrituras de compra e venda de cativos. The similarities and differences found reflected the characteristics of each source. The escrituras give the slave prices nearest of the market values; nevertheless, they do not encompass the slave population as a whole. On the other hand, the Lista de Classificação bring the information for almost the totality of the slaves, but is less accurate in the individual evaluations. Keywords: slave prices; slavery; coffee economy. 
INTRODUÇÃO

Preocupamo-nos, neste artigo, com os preços dos escravos no Brasil. Mais especificamente, dedicamos nossa atenção a quatro localidades paulistas situadas no Vale do Paraíba: Cruzeiro, Lorena, Guaratinguetá e Silveiras. Os informes por nós trabalhados referem-se ao triênio 1872/4 e provêm de dois distintos corpus documentais. Para Cruzeiro e Lorena, lançamos mão da Lista de classificação dos escravos para serem libertados pelo Fundo de Emancipação. No que respeita a Guaratinguetá e Silveiras, baseamo-nos em um conjunto de livros notariais destinados ao registro das transações de compra, venda, troca e dação in solutum de cativos. Conduzimos, pois, a análise dos preços dos escravos mediante a comparação dos dados fornecidos pelos dois tipos de documentos mencionados.

Muito embora inexistisse um comportamento homogêneo de todos os municípios que a integravam, pode-se afirmar que a porção paulista do Vale do $\mathrm{Pa}$ raíba, em seu conjunto, vivenciava o auge da produção cafeeira na primeira metade da década de 1870. Vale dizer, ainda que os sinais da decadência começassem a se fazer sentir em algumas localidades, o estabelecimento inequívoco da crise da cafeicultura valeparaibana demoraria ainda alguns lustros, durante os quais o café aceleraria sua "marcha" em direção ao Oeste. ${ }^{3}$

Assim, por exemplo, Sergio Milliet observa que, em 1854, a produção de café da zona "norte" da província (litoral norte e Vale do Paraíba) alçava-se a 2.737.639 arrobas, equivalentes a mais de três quartos $(77,5 \%)$ da produção paulista; no entanto, em 1886, esse porcentual declinava para $20,0 \%$, queda verificada também em termos absolutos (para 2.074.267 arrobas). ${ }^{4}$ Dentre as localidades aqui contempladas, provavelmente o caso de Guaratinguetá — das quatro, a localizada mais "a Oeste" — é aquele em que o declínio se veria mais postergado. De fato, como afirma Lucila Hermann, "a produção do café, em 1836, de 22.442 arrobas, eleva-se em 1854 a 100.885 e em 1886, seu período áureo, a 350.000 arrobas, decaindo sensivelmente depois ". ${ }^{5}$

A população dos municípios objeto deste estudo, em 1872, era de 38.294 indivíduos livres: 4.189 em Cruzeiro, 16.485 em Guaratinguetá, 7.743 em Lorena e 9.877 em Silveiras. ${ }^{6}$ Essas pessoas correspondiam a cerca de um quinto $(20,7 \%)$ do contingente livre existente no Vale do Paraíba paulista. Os escravos totalizavam 8.528 indivíduos, que representavam $18,3 \%$ da escravaria valeparaibana. Eram 742 em Cruzeiro, 4.352 em Guaratinguetá, 1.338 em Lorena e 2.096 em Silveiras. Do aludido total de cativos, 4.627 eram homens (54,3\%) e 3.901 eram mulheres (45,7\%). A razão de masculinidade assumia, nas distintas localidades, os valores seguintes: 134,1 em Cruzeiro, 111,1 em Guaratinguetá, 140,7 em Lorena e 117,0 em Silveiras. 


\section{AS FONTES}

O Fundo de Emancipação, do qual trata o capítulo II do regulamento aprovado pelo Decreto no 5.135 , de 13 de novembro de 1872 , previa que a alocação dos recursos para emancipação obedecesse à seguinte ordem: em primeiro lugar, libertar-se-iam os escravos participantes de relações familiares; em seqüência, os demais. Na libertação por famílias, estabelecia-se a classificação seguinte: $1^{\circ}$ ) os cônjuges que fossem escravos de diferentes senhores; $2^{\circ}$ ) os cônjuges que tivessem filhos nascidos livres em virtude da lei de 28 de setembro de 1871 - a Lei do Ventre-Livre - e menores de oito anos; $3^{\circ}$ ) os cônjuges que tivessem filhos livres menores de vinte e um anos; $4^{\circ}$ ) os cônjuges com filhos menores escravos; $5^{\circ}$ ) as mães com filhos menores escravos; $6^{\circ}$ ) os cônjuges sem filhos menores. Os demais cativos eram também ordenados: $1^{\circ}$ ) mãe ou pai com filhos livres; $2^{\circ}$ ) os de doze a cinqüenta anos de idade, começando pelos mais moços do sexo feminino, e pelos mais velhos do sexo masculino. ${ }^{7}$

A Lista de classificação por nós utilizada, referente aos municípios paulistas de Lorena e Cruzeiro, que se acha preservada no Arquivo do Estado de São Paulo, tem seu termo de encerramento datado aos 3 de maio de 1874. Dela consta, como se pode inferir a partir dos critérios de classificação dos escravos acima explicitados, a maior parte da população cativa daquelas localidades, radicando-se as maiores lacunas no contingente formado pelas pessoas com mais de 50 anos de idade. Dessa forma, se era de 2.080 o número de escravos existentes em Cruzeiro e Lorena no ano de 1872, alçou-se a 2.245 o total de cativos listados em maio de 1874.

De outra parte, para a maioria desses 2.245 indivíduos é fornecido o preço, decorrente de avaliação efetuada pela Junta de Classificação. ${ }^{8}$ Temos, pois, nesta fonte documental, a avaliação de quase toda a escravaria. Adicionalmente, constam do arrolamento os nomes do cativo e de seu respectivo proprietário, o número de matrícula do escravo, sua idade, estado conjugal, aptidão para o trabalho e profissão, ${ }^{9}$ além de um campo intitulado "pessoa de família", no qual se faz referência aos nomes dos pais ou de filhos menores, ou ainda apenas ao nome da mãe e, alternativamente, à condição de marido, mulher (isto é, esposa) ou mãe.

No caso de Guaratinguetá, servimo-nos de um livro notarial destinado unicamente ao lançamento das "escrituras de compras, vendas, trocas e de dação in solutum de escravos que tiverem de serem passadas pelo segundo Tabelião desta cidade e seu termo". Este documento, guardado no Arquivo Judiciário de Guaratinguetá, no Museu Frei Galvão, contém o registro de transações que cobrem o período de 15 de dezembro de 1872 a 2 de novembro de 1874. Para Silveiras, coletamos os dados — no $1^{\circ}$ Cartório de Cachoeira 
Paulista — a partir de três livros, similares àquele concernente a Guaratinguetá, e cujos termos de abertura estão datados, respectivamente, aos 27 de julho de 1871,28 de julho de 1873 e 28 de setembro de $1874 .^{10}$

As informações disponíveis em tais escrituras são as seguintes: data do registro; nomes do vendedor, do comprador e de seus procuradores, quando houver; local de moradia e títulos ou patentes militares do vendedor e do comprador; idade, sexo, estado conjugal, origem, naturalidade, cor e, eventualmente, caracteres físicos, atividade produtiva e forma prévia de aquisição do(s) escravo(s) transacionado(s); preço do(s) cativo(s); observação quanto à forma de quitação; informe sobre o recolhimento do imposto de meia sisa; transcrição dos dados da matrícula do(s) escravo(s) e, em alguns lançamentos, da procuração passada por vendedor e/ou comprador; nomes das testemunhas e, quando for o caso, da(s) pessoa(s) que assina(m) a rogo de uma ou das duas partes contratantes, em razão desta(s) não saber(em) escrever; fecho do tabelião e assinaturas.

\section{A HISTORIOGRAFIA}

Os preços dos escravos foram objeto da preocupação de diversos dentre os estudiosos do passado brasileiro. ${ }^{11}$ Assim, por exemplo, Jacob Gorender observa que

idade, sexo e robustez constituíram fatores de influência permanente na determinação do preço de compra do escravo. [... ] A par das qualidades intrínsecas, ou, em outras palavras, do valor de uso, influíam no preço do escravo fatores propriamente mercantis, atuantes no lado da oferta e no lado da demanda em sua oscilante correlação. ${ }^{12}$

Tais fatores, nas seções subseqüentes deste artigo, têm seu impacto evidenciado para os casos das localidades valeparaibanas examinadas, sobretudo aqueles de "influência permanente", uma vez que nos concentramos no período de tempo relativamente curto - 1872/1874 — coberto pelas fontes documentais compulsadas.

Em nossa historiografia, uma das verificações mais recorrentes no que respeita aos preços dos cativos é a de valores mais elevados para indivíduos do sexo masculino. A título ilustrativo, para o caso de Vassouras (RJ), no período de 1861 a 1886, lemos, em trabalho de Pedro C. de Mello, o seguinte: "em todos os anos, com apenas duas exceções, os preços dos escravos homens 
foram superiores aos das mulheres ${ }^{13} 0$ efeito da variável sexo, é evidente, imbricava-se, entre outros, àquele decorrente da variável idade do escravo. Dessa forma, por exemplo, para Guaratinguetá e Silveiras, no decurso das primeira e segunda metades da década de 1870, percebemos que “(...) regra geral, nos dois periodos e para todas as faixas etárias consideradas [menos de $10 ; 10-14 ; 15-24 ; 25-34 ; 35-44 ; 45-54 ; 55$ e mais anos], os preços médios dos homens superaram os das mulheres $" .{ }^{14}$ Mais ainda, nesse último estudo mencionado, realizado com base em escrituras de compra e venda de cativos, computamos as maiores freqüências de indivíduos transacionados, em ordem decrescente, nas faixas etárias dos 15 aos 24, dos 10 aos 14 e dos 25 aos 34 anos, e

(...) verificamos que nesses mesmos intervalos etários encontravam-se os escravos mais caros, fossem homens ou mulheres, (...) quanto mais jovens ou mais velhos, mais baratos eles eram em comparação àqueles em idades correspondentes ao maior vigor físico. ${ }^{15}$

Claro está que o aludido impacto sobre os preços de algumas das características demográficas dos escravos (sexo e idade), válido para a generalidade dos casos, poderia eventualmente modificar-se sob a ação de condicionantes outros, a exemplo da atividade produtiva por eles desempenhada. Assim, trabalhando este último informe para a freguesia do Pilar da cidade de Salvador, na província da Bahia, de 1838 a 1882, Marcílio et alii verificaram que "para a ocupação 'lavoura', conquanto o preço médio dos homens - $685 \$ 710$ - fosse maior do que o das mulheres - 615\$319 —, esta diferença não se revelou estatisticamente significante (...). Este resultado sugere que uma vez presente a ocupação lavoura o sexo deixa de ser relevante" ${ }^{16}$ Já para os cativos baianos "de profissão doméstica", as diferenças observadas entre o preço médio dos homens (Rs 882\$096) e o das escravas (Rs 772 \$915) mostrou-se significante do ponto de vista estatístico.

Muito embora os resultados encontrados para a freguesia do Pilar não sejam generalizáveis, ${ }^{17}$ é evidente a relevância da variável atividade produtiva do escravo na determinação de seu preço, mormente para os casos envolvendo maior especialização. Por exemplo, para Guaratinguetá e Silveiras na década de 1870, “(...) os preços médios dos indivíduos utilizados no serviço da lavoura foram, na maior parte dos casos, inferiores aos preços médios calculados nas atividades produtivas demandantes de maior qualificação". De outra parte, considerando conjuntamente as variáveis atividade produtiva e idade dos cativos, Carlos Lima, baseando-se em um conjunto de in- 
ventários post-mortem da cidade do Rio de Janeiro no período de 1789 a 1839, observa:

Os auges dos preços dos homens com ofícios artesanais em conjunto eram substancialmente mais tardios que os de todas as outras categorias, refletindo períodos mais longos de aprendizado. Artesãos pouco qualificados ficavam 'prontos' ao atingir idades próximas dos trinta anos, ao passo que os de ocupações mais sofisticadas só o faziam quase com quarenta. ${ }^{18}$

Por fim, duas referências adicionais à historiografia devem ser feitas no que tange aos "fatores propriamente mercantis" mencionados por Gorender. Tais referências permitem-nos melhor compreender o pano de fundo das experiências históricas tratadas nas seções seguintes deste artigo. Em primeiro lugar, os anos de 1872 a 1874 inserem-se num período de tendência crescente dos preços dos escravos, o que pode ser ilustrado, uma vez mais, com o recurso ao estudo de Pedro C. de Mello. Com base em 986 escrituras de vendas disponíveis para a localidade de Vassouras (RJ) no período 1861-86, observa o autor que

de um modo geral, os preços caem de 1861 a 1864, dado que em fins da década de 1850 tinha havido uma alta considerável dos preços. De 1865 a 1881 há uma tendência de alta, com flutuações. A partir desse ano os preços começam a cair continuamente, embora o pequeno número de observações a partir de 1884 não permita uma confiável definição quanto à representatividade dos preços médios apurados..$^{19}$

Em segundo lugar, e comparados à metade derradeira do decênio de 1870, os anos de 1872 a 1874 conformam um período anterior ao movimento de intensificação do tráfico interprovincial de cativos direcionado também ao Vale do Paraíba paulista e originado nas províncias ditas "do Norte". ${ }^{20}$

\section{OS ESCRAVOS}

Apresentamos, na Tabela 1, a distribuição dos escravos objeto deste estudo segundo sexo e de acordo com cinco faixas etárias. Com base nas escrituras de compra e venda disponíveis para Guaratinguetá e Silveiras, verificamos terem sido transacionados 163 cativos no período 1872/4, sendo 83 homens $(50,9 \%)$ e 80 mulheres (49,1\%). A composição sexual dos escravos transacionados mostrase, pois, mais equilibrada do que a observada a partir da lista de classificação de Cruzeiro e Lorena, na qual os porcentuais correlatos igualam-se, respectivamen- 
te, a $55,7 \%$ e 44,3\% (1.250 cativos do sexo masculino e 995 escravas). De fato, como informamos na Introdução, em 1872, nestas duas últimas localidades computaram-se razões de masculinidade da população escrava mais elevadas vis-⿳亠一⿵冂vis as calculadas para Guaratinguetá e Silveiras.

TABELA 1

DISTRIBUIÇÃO DOS ESCRAVOS SEGUNDO SEXO E FAIXAS ETÁRIAS

\begin{tabular}{lcccccccc}
\hline & \multicolumn{3}{c}{$\begin{array}{c}\text { Escrituras de compra e venda } \\
\text { Guaratinguetá e Silveiras, 1872/74 }\end{array}$} & \multicolumn{5}{c}{ Cruzeiro e Lorena, 1874 } \\
\hline Faixas etárias & Homens & $\%$ & Mulheres & $\%$ & Homens & $\%$ & Mulheres & $\%$ \\
\hline menores de 10 & 7 & 8,4 & 13 & 16,2 & 197 & 15,8 & 187 & 18,8 \\
\hline 10 a 14 & 16 & 19,3 & 13 & 16,2 & 165 & 13,2 & 113 & 11,4 \\
\hline 15 a 39 & 44 & 53,0 & 45 & 56,3 & 550 & 44,0 & 519 & 52,1 \\
\hline 40 a 59 & 12 & 14,5 & 7 & 8,8 & 320 & 25,6 & 165 & 16,6 \\
\hline 60 ou mais & 4 & 4,8 & 2 & 2,5 & 18 & 1,4 & 11 & 1,1 \\
\hline Total & 83 & 100,0 & 80 & 100,0 & 1.250 & 100,0 & 995 & 100,0 \\
\hline
\end{tabular}

Por outro lado, entre os cativos comercializados, é patente o predomínio daqueles com idades entre 15 e 39 anos: 53,0\% dos homens e 56,3\% das mulheres. Na lista de classificação, ainda que seja esta mesma faixa etária a que contém 0 maior número de escravos, os porcentuais correspondentes são mais baixos $(44,0 \%$ e 52,1\%). Claramente, o informe da lista reflete com maior proximidade o resultado do evolver demográfico da população cativa, o qual abrange não apenas o fluxo de indivíduos que integra o tráfico interno de escravos, mas igualmente o crescimento vegetativo (sobre este, cumpre referir, incide o impacto da família cativa). Assim, em comparação aos informes para Guaratinguetá e Silveiras, em Cruzeiro e Lorena têm maior importância relativa tanto as crianças menores de 10 anos, como - e principalmente - os escravos integrantes da quarta faixa etária (de 40 a 59 anos). Neste último caso, ademais, os porcentuais computados na lista de classificação encontram-se subestimados, tendo em vista os critérios de arrolamento dos indivíduos isolados, concentrado naqueles 
com idades entre 12 e 50 anos. Esses mesmos critérios, ressaltemos, explicam os porcentuais mais elevados, para os cativos com 60 anos ou mais, calculados a partir das escrituras de compra e venda.

\section{OS PREÇOS DOS ESCRAVOS}

Na Tabela 2 fornecemos o número absoluto e o preço médio dos escravos segundo o sexo e de acordo com distintas faixas etárias. Agrupam-se, uma vez mais, de um lado, os informes provenientes das escrituras de compra e venda de cativos e, de outro, os oriundos da lista de classificação dos escravos para emancipação. Como se pode observar, foi possível obter o informe do preço para apenas $57(68,7 \%)$ dos 83 homens e $41(51,3 \%)$ das 80 mulheres comercializadas, o que decorre do fato de que, para a maior parte das escrituras concernentes à venda de dois ou mais cativos, o preço constante do registro corresponder ao conjunto dos escravos. Na lista de classificação explicitou-se o preço de 1.004 $(80,3 \%)$ dos 1.250 homens e 745 (74,9\%) das 995 mulheres; neste último documento, não se informou o preço para nenhum dos indivíduos que apareciam apenas como filho(a) de outros cativos, o que explica a inexistência de informações de preços de escravos para Cruzeiro e Lorena na primeira das faixas etárias.

Considerando os dados da Tabela 2 conforme o sexo dos cativos, percebemos de imediato que, invariavelmente, nos dois tipos de fontes documentais e em todas as faixas etárias consideradas, os preços dos homens superavam o das escravas. Assim, por exemplo, tomada a totalidade dos cativos transacionados, 0 preço médio das mulheres $(920 \$ 854)$ correspondia a cerca de dois terços $(65,5 \%)$ do preço médio dos cativos do sexo masculino (1:405\$877); levando em conta a faixa etária dos 15 aos 39 anos isoladamente, o porcentual correlato iguala-se a $62,7 \%$. Na lista de classificação, o preço médio das 745 mulheres elevou-se a mais de quatro quintos $(83,3 \%)$ do preço médio dos 1.004 homens; levando-se em conta tão-somente os escravos com idades entre 15 e 39 anos, essa proporção se mantém $(81,2 \%){ }^{21}$

0 confronto entre os distintos manuscritos compulsados apresenta discrepâncias que nos interessam discutir. Verificamos que, com uma única exceção — os homens na faixa etária dos 40a 59 anos - , os preços médios informados na lista de classificação são maiores do que os computados com base nas escrituras de compra e venda de cativos. Tomando-se os indivíduos dos sexo masculino em seu conjunto, esse diferencial atinge a casa dos 10,7\%. Não obstante, alça-se a 32,3\% na faixa etária dos 10 aos 14 anos, e a 350,0\% entre os escravos com 60 ou mais anos. ${ }^{22} \mathrm{Na}$ faixa etária que concen- 
tra o maior número de cativos, o diferencial em questão iguala-se a 7,5\%. As discrepâncias em favor da lista de classificação são ainda mais significativas no caso das escravas. 0 preço médio das 745 mulheres listadas foi 40,8\% maior que o preço médio das 41 cativas transacionadas. Este porcentual iguala-se a 76,3\% na faixa etária dos 10 a 14 anos, a 39,2\% na dos 15 a 39 anos e a $130,2 \%$ na dos 40 a 59 anos.

\section{TABELA 2}

NÚMERO ABSOLUTO E PREÇO MÉDIO DE ESCRAVOS

HOMENS E DE ESCRAVAS, SEGUNDO FAIXAS ETÁRIAS

\begin{tabular}{|c|c|c|c|c|}
\hline \multirow{2}{*}{$\begin{array}{l}\text { Sexo/ } \\
\text { Faixas etárias }\end{array}$} & \multicolumn{2}{|c|}{$\begin{array}{c}\text { Escrituras de compra e venda } \\
\text { Guaratinguetá e Silveiras, 1872/74 }\end{array}$} & \multicolumn{2}{|c|}{$\begin{array}{l}\text { Lista de classificação } \\
\text { Cruzeiro e Lorena, } 1874\end{array}$} \\
\hline & Número & Preço médio (réis) & Número & Preço médio (réis) \\
\hline \multicolumn{5}{|l|}{ HoMENS } \\
\hline menores de 10 & 3 & $733 \$ 333$ & - & - \\
\hline 10 a 14 & 14 & $1: 146 \$ 429$ & 124 & $1: 516 \$ 935$ \\
\hline 15 a 39 & 33 & $1: 635 \$ 909$ & 542 & $1: 758 \$ 118$ \\
\hline 40 a 59 & 6 & $1: 300 \$ 000$ & 320 & $1: 291 \$ 407$ \\
\hline 60 ou mais & 1 & $100 \$ 000$ & 18 & $450 \$ 000$ \\
\hline Total & 57 & $1: 405 \$ 877$ & 1.004 & $1: 556 \$ 126$ \\
\hline \multicolumn{5}{|l|}{ MULHERES } \\
\hline menores de 10 & 2 & $475 \$ 000$ & - & - \\
\hline 10 a 14 & 8 & $784 \$ 375$ & 77 & $1: 383 \$ 117$ \\
\hline 15 a 39 & 29 & $1: 025 \$ 173$ & 494 & $1: 426 \$ 923$ \\
\hline 40 a 59 & 2 & $400 \$ 000$ & 164 & $920 \$ 731$ \\
\hline 60 ou mais & - & - & 10 & $375 \$ 000$ \\
\hline Total & 41 & $920 \$ 854$ & 745 & $1: 296 \$ 845$ \\
\hline
\end{tabular}

Se partirmos da hipótese de que os preços lançados nas escrituras de com- 
pra e venda são representativos das condições "de mercado" no momento em que as transações foram efetivadas, então nossos informes estariam apontando para a existência de uma superestimação das avaliações que compõem a lista de classificação dos cativos para emancipação. De fato, tudo indica que essas considerações são procedentes. De um lado, o das escrituras, a existência de um imposto a ser pago por ocasião do registro (a meia sisa) poderia decerto inibir, muitas vezes, a própria feitura desse registro; ${ }^{23}$ todavia, uma vez efetuado o lançamento, o valor do tributo, independentemente do preço do escravo, não tenderia a afetar este último no sentido de uma subestimação com vistas a diminuir o imposto a ser pago. ${ }^{24}$

No que respeita à lista de classificação, são vários os indícios da superestimação dos preços dos cativos. Em primeiro lugar, a grande freqüência de preços iguais para escravos de mesma idade. Não obstante não tenhamos dúvida de que a idade fosse uma das principais determinantes do valor do cativo, a repetição em demasia parece-nos indicar que, mesmo na classificação realizada nos anos 1870, acabou-se por usar, ainda que informalmente, algo parecido com a tabela de preços máximos que acompanha a regulamentação da classificação dos anos 1880. Como conseqüência, não apenas as avaliações da lista estariam superestimadas, mas igualmente se perderiam, em boa medida, os efeitos das características individuais dos cativos. Não deixa de ser também por esse motivo que tais avaliações, embora se mostrem em geral superiores aos preços verificados nas escrituras de compra e venda, não se mostrem igualmente superiores em todos os casos.

Tomemos como exemplo os indivíduos com 18 anos. Há 40 mulheres com essa idade na lista de classificação de Cruzeiro e Lorena. Para 11 delas, não dispomos do informe sobre o preço; uma está avaliada em Rs 1:300\$000; uma em Rs 1:500\$000; e 27 em Rs 1:400\$000. Vale dizer, mais de dois terços $(67,5 \%)$ das escravas de 18 anos - mais de nove décimos $(93,1 \%)$ se considerarmos apenas aquelas para as quais há o informe do preço - foram avaliadas em Rs 1:400\$000. Para os homens, as cifras correspondentes são as seguintes: há 53 deles com 18 anos, 9 avaliados em Rs 1:700\$000, 42 em Rs 1:800\$000 e 2 sem avaliação. Portanto, quase quatro quintos $(79,3 \%)$ dos cativos homens com aquela idade - proporção que se eleva a $82,4 \%$ se desconsiderarmos os dois homens sem preço — foram avaliados em Rs 1:800\$000. Parece-nos muito pouco razoável supor que nenhum desses 42 escravos - e, analogamente, nenhuma das 27 cativas às quais se atribuiu um preço comum — fosse portador de algum atributo individual que implicasse um preço diferenciado dos demais.

Adicionalmente, há que considerar serem os recursos do Fundo de Emancipação uma indenização paga aos escravistas pela libertação de seus cativos. E que as Juntas de Classificação seriam, sem dúvida, formadas por indivíduos de 
escol pertencentes à sociedade local. Mais ainda, mesmo que fosse - como de fato era - largo o espectro da distribuição da propriedade escrava, decerto os maiores dentre os proprietários de cativos estariam entre os mais destacados integrantes das elites locais. Em outras palavras, não seria de forma alguma um absurdo sugerir a possibilidade de uma certa "identidade de classe" entre os componentes das ditas juntas e aqueles identificados como os beneficiários dos pagamentos realizados pelo aludido fundo. Talvez fossem efetivamente as mesmas pessoas. A lista de classificação por nós analisada, por exemplo, vai assinada pelos seguintes indivíduos: Praxedes Luís Gonçalves, escrivão da Junta Municipal de Emancipação; José Neves Gonçalves da Silva Maciel, presidente da Junta de Classificação; Manoel Thomaz Pinto Pacca, promotor público; e Antonio Bruno de Godoy Bueno, coletor. Escravos pertencentes aos dois últimos estão arrolados no documento por eles assinado: o promotor público possuía dois cativos, e o coletor detinha um plantel formado por oito escravos.

Por fim, a superestimação das avaliações constantes da lista de classificação vê-se corroborada quando recorremos a um terceiro tipo de fonte documental: os inventários post-mortem. Conquanto sejam vários os casos identificados, servir-nos-emos de um único exemplo para ilustrar este ponto. Há 21 cativos na lista cujo proprietário declarado era Joaquim Pinto Ribeiro, 17 deles com 0 informe do preço. Possuímos, outrossim, o inventário desse escravista, de fevereiro de 1873, no qual sua viúva, Rita de Jesus do Nascimento, figurava como inventariante. Do arrolamento de bens constam 26 cativos. Conseguimos identificar no inventário todos os 17 cativos listados com preço pela Junta de Classificação. Em um único caso as avaliações foram idênticas. Os valores dos outros 16 indivíduos são menores no inventário. Os diferenciais variam muito: os preços na lista são de 6,7\% a 260,0\% mais elevados vis-à-vis os do inventário. Ademais, a variedade de preços neste último documento é maior ( 9 cifras diferentes versus 7 na lista de classificação). ${ }^{25}$

\section{OS PREÇOS DOS ESCRAVOS: SEXO E ATIVIDADE PRODUTIVA}

Nas Tabelas 3 e 4 apresentamos o número absoluto e o preço médio dos escravos de acordo com o sexo e a atividade produtiva declarada. Na primeira dessas tabelas estão os informes das escrituras de compra e venda (Guaratinguetá e Silveiras). A presença simultânea das duas informações mencionadas (preço e atividade produtiva) ocorreu para 61 dos cativos transacionados: 37 homens e 24 mulheres. Na Tabela 4 estão os dados da lista de classificação (Cruzeiro e Lorena): para 1.702 escravos (976 homens e 726 mulheres) coletamos a informação do preço e também a da atividade produtiva. 
Da observação das tabelas referidas percebemos, de pronto, a existência de uma certa correspondência entre o sexo e a atividade produtiva. Nas escrituras, as cozinheiras eram todas do sexo feminino, aí computadas as três que, além da cozinha, também trabalhavam no serviço da roça; de outra parte, eram homens o padeiro, o pagem, o pedreiro, e o escravo carreiro que também labutava na roça. Mesmo nas atividades mais comuns, ainda que não de forma absoluta, mantevese a correspondência com o sexo. Assim, dos 34 escravos vendidos cuja atividade era o "serviço da roça", 31 (91,2\%) eram homens; e dos 15 cativos empregados no "serviço doméstico", 13 (86,7\%) eram mulheres.

TABELA 3

NÚMERO ABSOLUTO E PREÇO MÉDIO DE ESCRAVOS SEGUNDO SEXO E ATIVIDADE PRODUTIVA DECLARADA NAS ESCRITURAS DE COMPRA E VENDA

(GUARATINGUETÁ E SiLVEIRAS, 1872/74)

\begin{tabular}{lcccc}
\hline & \multicolumn{2}{c}{ Homens } & \multicolumn{2}{l}{ Mulheres } \\
\hline $\begin{array}{l}\text { Atividades } \\
\text { produtivas }\end{array}$ & Número & Preço médio (réis) & Número & Preço médio (réis) \\
\hline serviço da roça & 31 & $1: 483 \$ 871$ & 3 & $700 \$ 000$ \\
\hline serviço doméstico & 2 & $1: 800 \$ 000$ & 13 & $1: 117 \$ 308$ \\
\hline $\begin{array}{l}\text { cozinheira } \\
\text { serviço da roça }\end{array}$ & - & - & 5 & $980 \$ 000$ \\
e cozinha & 1 & $1: 050 \$ 000$ & 3 & - \\
\hline padeiro & 1 & $2: 050 \$ 000$ & - & - \\
\hline pagem & 1 & $1: 900 \$ 000$ & - & - \\
\hline pedreiro & 1 & $1: 800 \$ 000$ & - & - \\
\hline carreiro e da roça & & & - & - \\
\hline
\end{tabular}


TABELA 4

NÚMERO ABSOLUTO E PREÇO MÉDIO DE ESCRAVOS SEGUNDO SEXO E ATIVIDADE PRODUTIVA DECLARADA NA LISTA DE CLASSIFICAÇÃO PARA EMANCIPAÇÃO

(CRUZEIRO E LORENA, 1874)

Homens

Mulheres

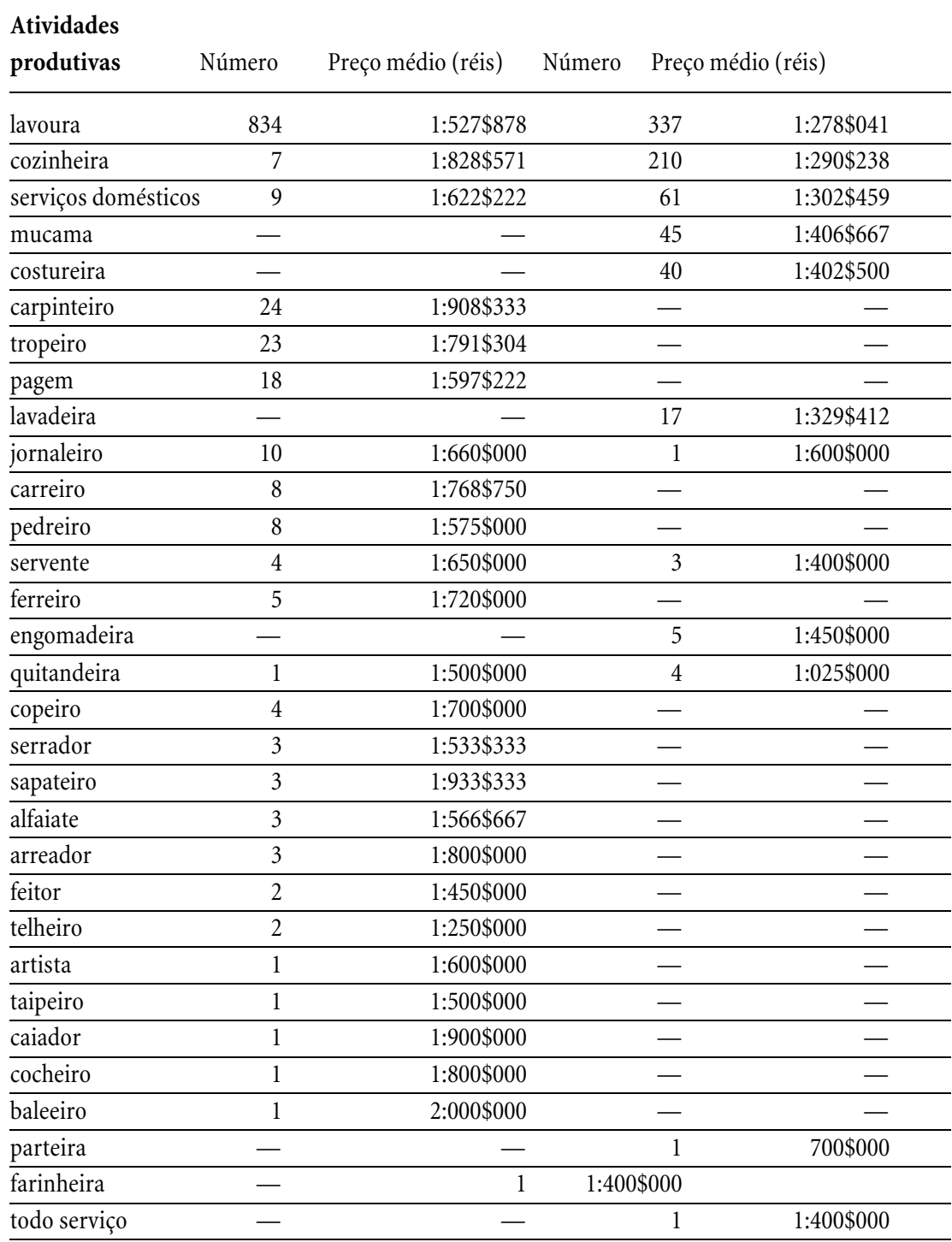


Essas “especializações” segundo o sexo podem ser verificadas, uma vez mais, com base na lista de classificação. Assim, eram apenas do sexo feminino: as 45 mucamas, as 40 costureiras, as 17 lavadeiras, as 5 engomadeiras, a parteira, a farinheira e a escrava para "todo serviço". Adicionalmente, as mulheres predominavam, ainda que não de modo absoluto, entre as seguintes atividades: cozinheira $(96,8 \%)$, serviços domésticos $(87,1 \%)$ e quitandeira $(80,0 \%)$. Já os homens correspondiam a todos os carpinteiros, tropeiros, pagens, carreiros, pedreiros, ferreiros, copeiros, serradores, sapateiros, alfaiates, arreadores, feitores, telheiros, artistas, taipeiros, caiadores, cocheiros e baleeiros. Predominavam também os homens entre os escravos empregados na lavoura $(71,2 \%)$, os jornaleiros $(90,9 \%)$ e os serventes $(57,1 \%)$.

Quando voltamos nossa atenção para os preços médios, notamos que, em ambas as fontes documentais, para todos os casos nos quais a atividade era desempenhada por homens e mulheres, os maiores preços médios foram aqueles concernentes aos escravos do sexo masculino. Esta afirmativa, portanto, permanece quer fossem ou não tais atividades executadas mais freqüentemente por escravas. Por exemplo, na lista de classificação, o preço médio dos sete cozinheiros (Rs 1:828\$571) foi 41,7\% mais elevado que o preço médio das 210 cozinheiras (Rs 1:290\$238). Outro exemplo, agora extraído das escrituras de compra e venda: o preço médio dos dois homens utilizados em "serviços domésticos" (Rs $1: 800 \$ 000)$ foi $61,1 \%$ superior ao preço médio das 13 cativas dedicadas à mesma atividade (Rs 1:117\$308).

Ainda em ambas as fontes documentais, observamos que a maior parte dos escravos estava alocada em serviços pouco exigentes no que concerne a habilidades específicas. Nas escrituras, $34(55,7 \%)$ dos 61 cativos trabalhavam no serviço da roça; na lista de classificação, 1.171 (68,8\%) dos 1.702 escravos labutavam na lavoura. De outra parte, como seria o esperado, em geral os preços médios dos cativos que executavam tarefas especializadas mostraram-se mais elevados que os preços médios dos trabalhadores da roça (lavoura). Por exemplo, entre os escravos do sexo masculino de Cruzeiro e Lorena, apenas ao quitandeiro e taipeiro, aos feitores e telheiros foram atribuídos preços médios inferiores aos trabalhadores da lavoura; e entre os homens comercializados, apenas o padeiro teve seu preço médio inferior ao dos cativos vinculados ao serviço da roça.

Por fim, a comparação entre os dois documentos reafirma a ocorrência de superestimação das avaliações da lista de classificação, porém apenas no caso dos escravos não envolvidos com atividades demandantes de maior especialização. Para a devida interpretação deste resultado devemos recorrer novamente aos critérios acima mencionados, que parecem ter norteado a atribuição de valores aos escravos pelas Juntas de Classificação. Desta forma, ao pautar-se por um conjunto de valores condicionados fundamentalmente pela idade e pelo se- 
xo dos indivíduos elencados, deu-se, sim, margem à superestimação dos preços em geral. Todavia, concomitantemente, subestimou-se a avaliação dos cativos mais preciosos. E eles eram mais preciosos não tão-somente por sua idade ou sexo, mas também pela atividade especializada que desempenhavam. Por exemplo, o pagem registrado nas escrituras de compra e venda foi transacionado por um preço (Rs 2:050\$000) 28,6\% superior ao preço médio dos pagens arrolados na lista de classificação (Rs 1:597\$222). ${ }^{26}$

\section{CONSIDERAÇÕES FINAIS}

Neste artigo estudamos os preços dos escravos para quatro localidades do Vale do Paraíba paulista: Cruzeiro, Lorena, Guaratinguetá e Silveiras. Nossa análise centrou-se na comparação de duas distintas fontes documentais que trazem o informe dos aludidos preços. Para Cruzeiro e Lorena utilizamo-nos da Lista de classificação para emancipação, a qual, resultante de regulamentação datada de fins de 1872, foi concluída em maio de 1874. Para Guaratinguetá e Silveiras, servimo-nos das escrituras de compra e venda de cativos registradas no decurso dos anos de 1872, 1873 e 1874. No período contemplado, os municípios de que tratamos vivenciavam o apogeu da economia cafeeira.

A comparação efetuada permitiu-nos observar que, em ambas as fontes, faziam-se mais numerosos os homens, principalmente na lista de classificação. Eram também mais numerosos os escravos com idades entre 15 e 39 anos, desta feita especialmente nas escrituras de compra e venda; em tal faixa etária, adicionalmente, computaram-se os maiores preços médios. Os cativos do sexo masculino mostraram-se, para todas as faixas etárias consideradas, mais valiosos que as escravas. Por fim, verificamos a existência de uma certa correspondência entre as variáveis sexo e atividade produtiva dos escravos, sendo que a grande maioria dos cativos estava alocada em atividades de baixa especialização (serviço da roça, lavoura).

Não obstante os resultados similares apontados, foram igualmente significativas as discrepâncias percebidas entre os documentos estudados. Assim, exceto para os homens de 40 a 59 anos de idade, os preços médios calculados a partir da lista de classificação foram superiores àqueles coletados nas escrituras de compra e venda: cerca de $10 \%$ superiores no caso dos indivíduos do sexo masculino, porcentual que se eleva a aproximadamente $40 \%$ no caso das mulheres. No entanto, considerada a informação sobre as atividades produtivas dos cativos, verificamos concentrarem-se na atividade que congregava o maior número de indivíduos (serviço da roça e lavoura) as situações em que os preços eram 
inferiores nas escrituras; nas demais ocupações, mostraram-se freqüentes os casos em que os menores preços eram exatamente os da lista de classificação.

As semelhanças e diferenças apontadas refletem as características próprias a cada uma das fontes documentais que utilizamos. Por exemplo, a presença mais intensa, nas escrituras, dos escravos na faixa etária dos 15 a 39 anos, revela a maior proximidade dessa fonte com relação às condições de comercialização que marcavam o tráfico interno de cativos. Por outro lado, a maior importância relativa, na lista de classificação, das crianças e dos escravos com idades entre 40 e 59 anos, atesta ser este último documento um retrato que melhor corresponde ao conjunto da escravaria existente nas localidades analisadas; um retrato, façamos a ressalva, ainda imperfeito, como se depreende da evidente subestimação havida com respeito aos indivíduos com mais de 50 anos de idade.

De fato, os critérios que subjazem à confecção da lista de classificação podem ser, em grande medida, apontados como responsáveis também pelas disparidades observadas na comparação dos preços médios lá fornecidos vis-àvis os constantes das escrituras de compra e venda. Tais critérios acarretaram, de um lado, a mencionada superestimação dos preços em geral e, de outro, uma menor variabilidade dos preços entre indivíduos de mesmo sexo e idade, impedindo provavelmente, em muitos casos, que caracteres individuais importantes, tais como as habilidades necessárias à execução de ofícios específicos, fossem levados devidamente em conta na definição das avaliações que compõem o aludido documento.

Vale dizer, tratamos de dois documentos fundamentais para o estudo dos preços dos escravos brasileiros, um dos quais - as escrituras de compra e venda - nos fornece o dado de forma mais próxima do mercado, porém abrange parcela não tão representativa da população quanto a parcela compreendida pelo outro - a lista de classificação para emancipação - que, por sua vez, ao passo que nos brinda com essa maior abrangência, encerra maiores dificuldades quando se trata das avaliações individuais dos cativos arrolados.

\section{NOTAS}

${ }^{1}$ Professor Doutor da FEA/USP. Este artigo contou com o auxílio financeiro da Fundação de Amparo à Pesquisa do Estado de São Paulo — FAPESP.

${ }^{2}$ Professor Doutor da FEA/USP e do Programa de Pós-Graduação em História Econômica da FFLCH/USP.

${ }^{3}$ Assumimos, portanto, para o Vale do Paraíba paulista, tomado como um todo, uma cronologia da crise cafeeira similar à propugnada para o Rio de Janeiro, em SLENES, Robert W. Grandeza ou decadência? 0 mercado de escravos e a economia cafeeira da Província do Rio de Janeiro, 1850- 
1888. In: COSTA, Iraci del Nero da. Brasil: história econômica e demográfica. São Paulo: IPE/USP, 1986, pp. 103-155. Procedimento próximo ao aqui adotado encontra-se em MARCONDES, Renato Leite. A arte de acumular na economia cafeeira: Vale do Paraiba, século XIX. Lorena: Stiliano, 1998, cap. 6.

${ }^{4}$ Cf. MILLIET, Sergio. Roteiro do café e outros ensaios. 2.ed. São Paulo: BIPA-Editora, 1946, pp. 18-20.

${ }^{5}$ HERRMANN, Lucila. Evolução da estrutura social de Guaratinguetá num periodo de trezentos anos. Ed. facsimilada. São Paulo: IPE/USP, 1986, p. 115.

${ }^{6}$ Cf. MARQUES, Manuel E. de Azevedo. Apontamentos históricos, geográficos, biográficos, estatísticos e noticiosos da Província de São Paulo, seguidos da cronologia dos acontecimentos mais notáveis desde a fundação da Capitania de São Vicente até o ano de 1876. São Paulo: Comissão do IV Centenário da Cidade de São Paulo, 1953, v. 2, pp. 181182.

${ }^{7}$ Cf. Collecção das leis do império do Brasil de 1872. Rio de Janeiro: Typographia Nacional, 1873, v. 2., p. 1.059. Ver também GRAF, Márcia E. de Campos. População escrava da Província do Paraná, a partir das listas de classificação para emancipação (1873 1886). Dissertação de Mestrado. Curitiba: Universidade Federal do Paraná, 1974, cap. 1, pp. 537.

${ }^{8}$ "Para a indenização referente aos escravos a serem emancipados, o preço seria fixado tendo em consideração as condições de idade, saúde e profissão do escravo. Na avaliação seria levada em conta qualquer quantia que o escravo houvesse pago a seu proprietário em favor de sua alforria, devendo essa circunstância ser declarada no termo de avaliação" (GRAF, op. cit., p. 18).

"Quanto aos quesitos “aptidão para o trabalho" e "profissão", vale observar que, enquanto o último contemplava o informe da ocupação/atividade produtiva do cativo, o primeiro trazia uma apreciação de suas condições ("bom", "ruim", "sofrível", "doente", etc.).

${ }^{10} \mathrm{~A}$ título ilustrativo, transcrevemos o termo de abertura de um dos três livros compulsados: "Servirá este livro para nele se lançarem as escrituras de compra e venda de escravos celebradas no Cartório do Tabelião Público deste Termo. Silveiras, digo, suas folhas vão numeradas e rubricadas por mim com a rubrica que uso [ rubrica ]. Silveiras 28 de julho de 1873. Francisco de Paula Pereira Barbosa. Juiz Municipal do Termo". Ademais, a aludida fonte documental, para as mesmas localidades referidas, e desta feita levando em conta todo o decênio de 1870, foi objeto de nossa análise em MOTTA, José Flávio \& MARCONDES, Renato Leite. 0 comércio de escravos no Vale do Paraíba paulista: Guaratinguetá e Silveiras na década de 1870. Estudos Econômicos. São Paulo: IPE/USP, v. 30, n. 2, pp. 267-299, abr./jun. 2000.

${ }^{11}$ Salientemos, de pronto, não existir qualquer pretensão nossa, nesta breve seção acerca da historiografia, de cobrir de maneira exaustiva os trabalhos que se dedicaram, direta ou indiretamente, à temática dos preços dos cativos.

${ }^{12}$ GORENDER, Jacob. O escravismo colonial. 4.ed. rev. e ampliada. São Paulo: Ática, 1985, pp. 186-187. 
${ }^{13}$ MELLO, Pedro Carvalho de. A economia da escravidão nas fazendas de café: 1850 1888. Rio de Janeiro: PNPE / ANPEC, 1984, v. 1, p. 138.

${ }^{14}$ MOTTA, José Flávio \& MARCONDES, Renato Leite. Op. cit., p. 278.

${ }^{15}$ Idem, pp. 279-280.

${ }^{16}$ MARCÍLIO, Maria Luíza et alii. Considerações sobre o preço do escravo no período imperial: uma análise quantitativa (baseada nos registro de escritura de compra e venda de escravos na Bahia). Anais de História. Assis: FFCL de Assis, n. 5, pp. 179-194, 1973.

${ }_{17}$ 'Tomando-se tão-somente os cativos 'da roça', nossos dados não corroboram a verificação acima citada para o caso dos escravos da freguesia do Pilar, na Bahia. Mesmo nessa atividade 'pouco qualificada', os preços médios das mulheres foram menores que os dos homens nas localidades valeparaibanas que examinamos [Guaratinguetá e Silveiras] : menos da metade (47,2\%) no periodo 1871-4, e menos de dois terços $(61,3 \%)$ entre 1875 e 1879” (MOTTA, José Flávio \& MARCONDES, Renato Leite. Op. cit., p. 281).

${ }^{18}$ LIMA, Carlos A. M. Sobre a lógica e a dinâmica das ocupações escravas na cidade do Rio de Janeiro (1789-1835). In SOUSA, Jorge Prata de (org.). Escravidão: ofícios e liberdade. Rio de Janeiro: Arquivo Público do Estado do Rio de Janeiro — APERJ, 1998, p. 25.

${ }^{19}$ MELLO, Pedro Carvalho de. op. cit., v. 1, pp. 137-138. Por outro lado, restringindo-nos à década de 1870 e a duas das quatro localidades valeparaibanas examinadas neste artigo, percebemos “(...) nitidamente que os preços médios levantados para os anos de 1875 a 1879 são maiores vis-à-vis os observados no periodo de 1871 a 1874" (MOTTA, José Flávio \& MARCONDES, Renato Leite. op. cit., p. 277).

${ }^{20}$ De fato, especialmente na segunda metade da década em tela, foram inúmeros os cativos vindos dessas províncias, a exemplo, entre outras, da Bahia, da Paraíba, de Pernambuco e, sobretudo, do Ceará. São conhecidas as dificuldades vivenciadas à época por aquela região, violentamente castigada pelas secas. Por exemplo, em seu estudo sobre a indústria açucareira em Pernambuco, escreve Peter Eisenberg: "O tráfico interprovincial chegou ao auge na década de 1870 em virtude das severas secas nordestinas que forçaram a liquidação dos ativos fixos, como os escravos. O total de escravos embarcados para o sul, após 1876, foi tão elevado que as províncias compradoras — Rio de Janeiro, São Paulo e Minas Gerais - impuseram elevados tributos à importação de escravos, em 1880 e 1881. (...) Os tributos acabaram com o tráfico interprovincial de escravos" (EISENBERG, Peter. Modernização sem mudança: a indústria açucareira em Pernambuco, 18401910. Rio de Janeiro: Paz e Terra ; Campinas: Universidade Estadual de Campinas, 1977, pp. 175177).

${ }^{21}$ Cabe observar que, na nova matrícula dos cativos brasileiros, determinada pela Lei no 3.270, de 28 de setembro de 1885, e regulamentada pelo Decreto no 9.517 , de 14 de novembro de 1885 , “o valor seria declarado pelo proprietário do escravo, não excedendo o preço máximo regulado pela idade do matriculado, conforme tabela que consta do artigo $1^{\circ}$ da Lei [...] Sendo que o valor dos escravos do sexo feminino teria um abatimento de 25\% sobre os preços estabelecidos" (GRAF, op.cit., p. 20). 
${ }^{22}$ Salientemos que foi coletado o preço de apenas um escravo com idade superior a 59 anos nas escrituras de compra e venda de cativos trabalhadas neste artigo.

${ }^{23} \mathrm{~A}$ venda, nas localidades paulistas por nós examinadas, de cativos vindos das províncias do Norte e Nordeste era, amiúde, realizada por meio de procuradores dos vendedores. Muitos dentre esses procuradores, em diversos casos moradores no Rio de Janeiro, seriam, de fato, legítimos proprietários dos escravos que, em verdade, ora revendiam, mas preferiam utilizar-se da procuração como forma de escapar ao recolhimento da meia sisa quando da compra dos cativos junto aos proprietários originais. Essa a hipótese aventada, por exemplo, por Robert Slenes, com base em dados sobre Campinas (SP) e Vassouras (RJ): “Acontece que normalmente o tráfico interno de escravos (entre municípios e entre províncias) se fazia através de intermediários. As vezes, o intermediário era um simples procurador (de verdade), representante do vendedor ou do comprador. Na grande maioria dos casos, no entanto, o intermediário era um negociante que comprava o escravo do vendedor original e vendia-o depois ao comprador final, quando não a outro mercador. Contudo, nesses casos, não se costumava fazer uma escritura de compra e venda para cada transação efetuada. Normalmente se disfarçava a transferência de posse para um negociante intermediário com uma procuração bastante, que conferia a este plenos poderes para vender o escravo onde e por quanto quisesse. Se o negociante passava o escravo para outro intermediário, também não o fazia por escritura mas por um subestabelecimento da procuração. Era comum, no caso de escravos vindos de longe, que houvesse uma seqüência de subestabelecimentos entre o 'procurador' e o comprador final. $O$ objetivo desses subterfúgios era de evitar o pagamento do imposto de compra e venda cada vez que o escravo passava de um dono para outro" (SLENES, R. W. Grandeza ou decadência? 0 mercado de escravos e a economia cafeeira da província do Rio de Janeiro, 1850-1888. In: COSTA, I. del N. da (org.). Brasil: história econômica e demográfica. São Paulo: IPE/USP, pp. 103-155, 1986.1986, p. 118).

${ }^{24}$ Também destituída de maiores efeitos sobre o preço do escravo seria a despesa havida com o selo, relativamente reduzida, ainda que proporcional ao valor da escritura. Assim, por exemplo, na "escritura de venda de uma escrava de nome Benedicta, que passa João Ramos Leite ao Doutor José Manoel de Castro Santos, por 1:000\$000”, lançada em Guaratinguetá aos 14 de abril de 1873, o comprador recolheu Rs 30\$000 de meia sisa e pagou Rs $1 \$ 000$ de selo; já no caso da cativa Ignês, vendida por Manoel José de Castro a José Joaquim da Rocha, pela quantia de Rs 600\$000, também na localidade de Guaratinguetá em 18 de maio de 1873, foram recolhidos os mesmos Rs 30\$000 de meia sisa, porém pagos apenas Rs 600 de selo.

${ }^{25} \mathrm{O}$ inventário referido encontra-se depositado no Arquivo Municipal de Lorena. A relação dos bens inventariados permite-nos, outrossim, avançar algumas considerações sobre o valor atribuído aos escravos em comparação aos demais itens arrolados. Desta forma, se um escravo do sexo masculino em idade ativa valia pouco mais de um conto e quinhentos mil réis na primeira metade da década de 1870, computamos, no inventário em tela, os seguintes bens e suas avaliações respectivas: uma roda de ralar mandioca e prensa Rs $25 \$ 000 ; 40$ arrobas de fumo Rs $400 \$ 000$; um alambique de cobre Rs 100\$000; duas pipas boas Rs $100 \$ 000$; um macho arreado com cangalha Rs 120\$000; uma égua tordilha Rs 60\$000; casas de morada da fazenda, casas de pipa, de tropa, paiol, tulhas, moinho e monjolos e todas as mais benfeitorias de terreiro Rs 2:350\$000; 
um engenho de moer cana e casas do mesmo e corredor de alambique Rs 500\$000; as terras da fazenda calculadas em 180 alqueires de plantação de milho (mais ou menos) Rs 12:600\$000; 2.000 pés de café Rs $500 \$ 000$; um canavial novo Rs $250 \$ 000$; 4.000 pés de café com o fruto pendente Rs 1:600\$000, e as terras do sítio calculadas em 58 alqueires Rs 5:800\$000 (cf. Inventário de Joaquim Pinto Ribeiro, 1873, $2^{\circ}$ Ofício - Arquivo Municipal de Lorena). Destarte, o valor de um cativo homem em idade produtiva corresponderia, em nosso exemplo, a cerca de 16 vezes 0 de um alambique, a quase 30 vezes o de uma égua, a aproximadamente o mesmo de 4.000 pés de café com frutos, e ao redor de 25 alqueires de terra. Essa última relação, inferida a partir de um inventário post-mortem, vê-se em boa medida corroborada pelo exemplo de uma escritura de permuta de terras por escravos, registrada aos 18 de dezembro de 1871 e preservada no Cartório do $2^{\circ}$ Ofício de Notas de Casa Branca, localidade do "Oeste" cafeeiro paulista. Por essa escritura, Manoel Rodrigues Olegário, negociante domiciliado em Casa Branca, e d. Ritta Alves Moreira, lavradora domiciliada no distrito dessa mesma vila, ajustam o seguinte: ele dá 32 alqueires de terras de cultura na Fazenda Rio Doce e Ribeirão de São João, que adquiriu por compra, no valor de Rs 1:280\$000; ela, em troca, dá dois escravos (Luzia, 25 anos de idade, preta, solteira, e seu filho Adão, de 5 anos, ambos naturais de Casa Branca), que houve em sua meação por falecimento de seu marido, Ambrósio Joaquim Furtado, ambos os cativos no valor de Rs 1:500\$000, “... voltando o primeiro nomeado à segunda, a quantia de duzentos e vinte mil réis, que recebeu”.

${ }^{26} \mathrm{O}$ menor preço verificado na lista para o caso dos escravos pagens foi igual a Rs 1:000\$000 (Evaristo, de 25 anos), e o maior alçou-se a Rs 2:000\$000 (Onofre, de 20 anos de idade). 